\title{
BRIP1 inhibits the tumorigenic properties of cervical cancer by regulating RhoA GTPase activity
}

\author{
WEI ZOU*, XIANGDONG MA*, WEI HUA, BILIANG CHEN, YANHONG HUANG, \\ DETANG WANG and GUOQING CAI
}

Department of Obstetrics and Gynecology, Xijing Hospital, The Fourth Military Medical University, Xi'an, Shaanxi 710032, P.R. China

Received November 17, 2014; Accepted October 28, 2015

DOI: $10.3892 / 01.2015 .3963$

\begin{abstract}
Breast cancer 1, early onset (BRCA1)-interacting protein 1 (BRIP1), a DNA-dependent adenosine triphosphatase and DNA helicase, is required for BRCA-associated DNA damage repair functions, and may be associated with the tumorigenesis and aggressiveness of various cancers. The present study investigated the expression of BRIP1 in normal cervix tissues and cervical carcinoma via reverse transcription-quantitative polymerase chain reaction (RT-qPCR) and immunohistochemistry assays. BRIP1 expression was observed to be reduced in squamous cancer tissue and adenocarcinoma compared with normal cervix tissue, and there were significant correlations between the reduction in BRIP1 expression and unfavorable variables, including the International Federation of Gynecologists and Obstetricians stage and presence of lymph node metastases. In order to elucidate the role of BRIP1 in cervical cancer, a BRIP1 recombinant plasmid was constructed and overexpressed in a cervical cancer cell line (HeLa). The ectopic expression of BRIP1 markedly inhibited the tumorigenic properties of HeLa cells in vitro, as demonstrated by decreased cell growth, invasion and adhesion, and increased cell apoptosis. In addition, it was identified that the inhibitory tumorigenic properties of BRIP1 may be partly attributed to the attenuation of RhoA GTPase activity. The present study provides a novel insight into the essential role of BRIP1 in cervical
\end{abstract}

Correspondence to: Professor Guoqing Cai, Department of Obstetrics and Gynecology, Xijing Hospital, The Fourth Military Medical University, 127 Changle West Road, Xi'an, Shaanxi 710032, P.R. China

E-mail: zouwei1968@163.com

*Contributed equally

Key words: breast cancer 1, early onset-interacting protein 1, cervical cancer, cell apoptosis, Ras homolog gene family, member A guanosine-5'-triphosphatase cancer, and suggests that BRIP1 may be a useful therapeutic target for the treatment of this common malignancy.

\section{Introduction}

Cervical cancer is the second most common cancer in women globally, and is a significant cause of morbidity and mortality $(1,2)$. According to the US Center for Disease Control and Prevention, there are $>11,000$ new cases of cervical cancer diagnosed every year in the United States, and 4,000 people die annually as a result of this disease (3). Although invasive cervical cancer rates have decreased steadily over recent decades, due to a lack of screening programs, cervical cancer is predominantly detected during advanced stages (IIB and IIIB) in developing countries (4). Approximately half of patients with advanced cervical cancer will develop recurrence or metastases within the initial two years following completion of therapy (5).

Molecular and epidemiological studies have revealed that human papillomavirus (HPV) infection may be a prerequisite for cervical cancer development, and host genetic variations that control cell division and the maintenance of genome integrity (for example, DNA repair) may determine the risk of an individual developing cervical cancer (6-8). In order to reveal a patient's genetic susceptibility to cervical cancer, it is necessary to identify novel molecular markers that are able to predict the development of cervical cancer.

Breast cancer 1, early onset (BRCA1)-interacting protein 1 (BRIP1), which is also known as BRCA1-associated C-terminal helicase 1 , and located on chromosome $17 \mathrm{q} 23$, is part of the DEAH helicase family. BRIP1 directly interacts with the BRCA1 C terminus domain of BRCA1, and is important in DNA damage repair (9-13). The specific interaction between phosphorylated BRIP1 and BRCA1 is regulated by the cell cycle and is crucial for DNA damage-induced checkpoint control during the G2-to-M-phase transition $(14,15)$. Given the crucial function of BRIP1 in the regulation of normal cell cycle progression and DNA repair, the BRIP1 gene represents a good candidate for prediction of genetic susceptibility to cancer. Accumulating evidence has suggested that BRIP1 may have an anti-oncogenic role, and downregulation of BRIP1 has been observed in multiple types of cancer (16-19). 
The aims of the present study were to evaluate the role of BRIP1 in the tumorigenic properties of cervical cancer, and to identify whether the Ras homolog gene family, member A guanosine-5'-triphosphate-ase (RhoA GTPase) has a role in the antitumor effects of BRIP1.

\section{Materials and methods}

Reagents. Monoclonal rabbit anti-human BRIP1 (cat. no. 4578; 1:1,000), cleaved caspase-3 (cat. no. 9661; 1:1,000), B-cell lymphoma 2 (cat. no. 2870; 1:1,000), tubulin (cat. no. 5335; 1:1,000), RhoA-GTP (cat. no. 2461; 1:1,000), RhoA (cat. no. 2117; 1:1,000), Ras-related C3 botulinum toxin substrate 1 (Rac1)-GTP (cat. no. 8815; 1:1,000) and monoclonal mouse anti-human Rac1 (cat. no. 4651; 1:1,000) antibodies were obtained from Cell Signaling Technology, Inc. (Danvers, MA, USA). Lysophosphatidic acid (LPA) was obtained from Cayman Chemical Co. (Ann Arbor, MI, USA).

Patient and tissue samples. Human cervical carcinoma samples $(n=225)$ were randomly collected from surgical specimens in the Department of Obstetrics and Gynecology, Xijing Hospital (Xi'an, China) between 2012 and 2013. None of the patients had received radiotherapy or chemotherapy prior to surgery. Additionally, normal cervical specimens were obtained from 30 patients with uterine fibroids, who had undergone total hysterectomy at Xijing Hospital. All tissue samples were either immediately frozen in liquid nitrogen for later use in reverse transcription-polymerase chain reaction (RT-PCR) analysis, or fixed in $10 \%$ formalin and embedded in paraffin for immunohistochemical analysis. Pathologists at Xijing Hospital verified the diagnoses of the tissue samples. All samples were obtained with written informed consent, and the ethics committee of Xijing Hospital approved the protocol for the present study.

Cell culture. Normal cervix cell lines (End1 and Ect1) and a cervical cancer cell line (HeLa) were purchased from American Type Culture Collection (Manassas, VA, USA). The cells were maintained in Dulbecco's modified Eagle's medium (DMEM) with high glucose (Gibco; Thermo Fisher Scientific, Waltham, MA, USA) supplemented with $10 \%$ fetal bovine serum (FBS; Hyclone; GE Healthcare Life Sciences, Logan, UT, USA) at $37^{\circ} \mathrm{C}$ in a cell culture incubator with an atmosphere of $5 \% \mathrm{CO}_{2}$.

$R T-q P C R$. Total RNA was extracted using TRIzol ${ }^{\circledR}$ reagent (Invitrogen; Thermo Fisher Scientific, Waltham, MA, USA), and first-strand complementary DNA was reverse transcribed from RNA using the Reverse Transcription System kit (Promega Corp., Madison, WI, USA). RT-qPCR was performed using a LightCycler96 ${ }^{\circledR}$ (Roche Diagnostics $\mathrm{GmbH}$, Mannheim, Germany). PCR cycling conditions were as follows: 40 cycles at $98^{\circ} \mathrm{C}$ for $30 \mathrm{sec}, 58^{\circ} \mathrm{C}$ for $90 \mathrm{sec}$, and $72^{\circ} \mathrm{C}$ for $30 \mathrm{sec}$, with a final extension step at $72^{\circ} \mathrm{C}$ for $10 \mathrm{~min}$. The messenger RNA (mRNA) expression levels, which were normalized against glyceraldehyde 3-phosphate dehydrogenase (GAPDH), were calculated and expressed as $2^{-\Delta \Delta C q}$. The primer sequences utilized were as follows: BRIP1 sense, 5'-CAATGCCCGTGCTGTCA-3' and antisense, 5'-ATCTGC
TGCCGTACCCATTTA-3'; GAPDH sense, 5'-GCACCGTCA AGGCTGAGAAC-3' and antisense, 5'-TGGTGAAGACGC CAGTGGA-3' (Jie Li Biology, Shanghai, China).

Immunohistochemistry. Paraffin-embedded tissue sections (8- $\mu \mathrm{m}$ thick) were dewaxed, rehydrated and immersed in methanol containing $0.3 \%$ hydrogen peroxide for $30 \mathrm{~min}$ in order to block any endogenous peroxidase activity. Subsequently, the slides were incubated at $89^{\circ} \mathrm{C}$ in $10 \mathrm{mM}$ sodium citrate buffer (pH 6.0) for $30 \mathrm{~min}$ for antigen retrieval. Primary rabbit antihuman BRIP1 polyclonal antibodies (cat. no. HPA005474; Sigma-Aldrich, St. Louis, MO, USA) were diluted to 1:100 and incubated with the tissue sections overnight at $4^{\circ} \mathrm{C}$. The slides were subsequently incubated with anti-rabbit horseradish peroxidase-conjugated secondary antibodies (Nichirei Bioscience Inc., Tokyo, Japan) for $1 \mathrm{~h}$. Finally, the visualization signal was developed by incubation in 3,3'-diaminobenzidine in buffered substrate (Nichirei Bioscience) for $5 \mathrm{~min}$.

Plasmid construction and transfection. In order to generate the BRIP1 recombinant plasmid, the full-length translated region of the BRIP1 gene was amplified using PCR with the following primers: forward, 5'-GCAATGTCTTCAATGTGG TCT-3' and reverse, 5'-GGATTTTACTTAAAACCAGGA AA-3'. PCR was performed under the following conditions: 30 cycles at $98^{\circ} \mathrm{C}$ for $15 \mathrm{sec}, 58^{\circ} \mathrm{C}$ at $90 \mathrm{sec}$, and $72^{\circ} \mathrm{C}$ for $20 \mathrm{sec}$, with a final extension step at $72^{\circ} \mathrm{C}$ for $5 \mathrm{~min}$. The resulting PCR amplicons of BRIP1 were cloned into the pGEM $^{\circledR}-\mathrm{T}$ vector (Promega Corp.). The correct clones were confirmed via sequencing. The cells were grown in Opti-MEM medium (Invitrogen; Thermo Fisher Scientific) for $24 \mathrm{~h}$ prior to transfection. The cells were transfected with plasmid (200 ng) using the Lipofectamine ${ }^{\mathrm{TM}} 2000$ reagent (Invitrogen; Thermo Fisher Scientific) according to the manufacturer's protocol. The following assays were performed $48 \mathrm{~h}$ subsequent to transfection.

Cell proliferation assays. HeLa cells were plated into 96-well microplates (Beyotime Institute of Biotechnology, Haimen, China) at a density of $10^{3}$ cells/well. Cell proliferation was evaluated using the Cell Proliferation kit I, containing 3-(4,5-dimethylthiazol-2-yl)-2,5-diphenyltetrazolium bromide (MTT; Roche Diagnostics $\mathrm{GmbH}$ ) and was performed according to the manufacturer's protocol. The absorbance value (A) at $570 \mathrm{~nm}$ was measured using a Benchmark microplate reader (Bio-Rad Laboratories, Inc., Hercules, CA, USA).

Transwell migration assays. Transwell migration assays were performed with $6.5-\mathrm{mm}$ diameter cell culture inserts $(8-\mu \mathrm{m}$ pore size; Corning Life Sciences, Corning, NY, USA) in 24-well culture plates. The Transwell inserts were coated with Matrigel (80 $\mu \mathrm{g} /$ well; BD Biosciences, San Jose, CA, USA) for the invasion assays. The cells $\left(5 \times 10^{4} /\right.$ well $)$ were added to the upper chamber in $200 \mu \mathrm{l}$ of serum-free DMEM high glucose medium with $0.1 \%$ bovine serum albumin (Gibco; Thermo Fisher Scientific), and subsequently placed into 24-well plates in DMEM-high glucose medium with $10 \%$ FBS. Following $24 \mathrm{~h}$ of incubation, non-migrated cells were removed from the upper surface with cotton buds, and the cells that migrated to 
A

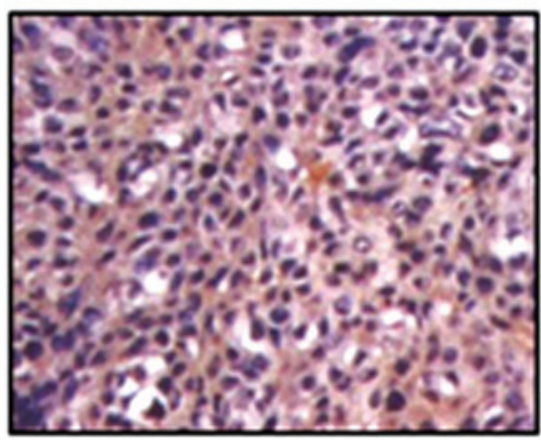

Normal cervix tissue

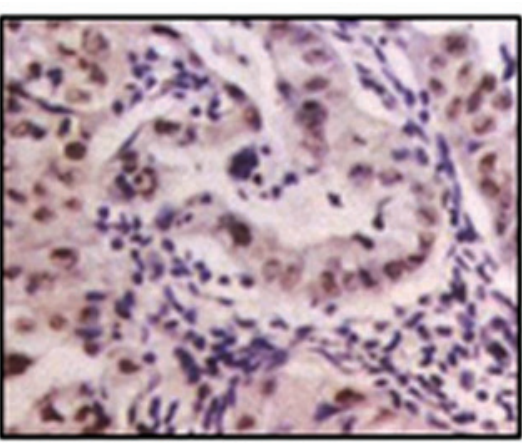

Squamous cancer tissue

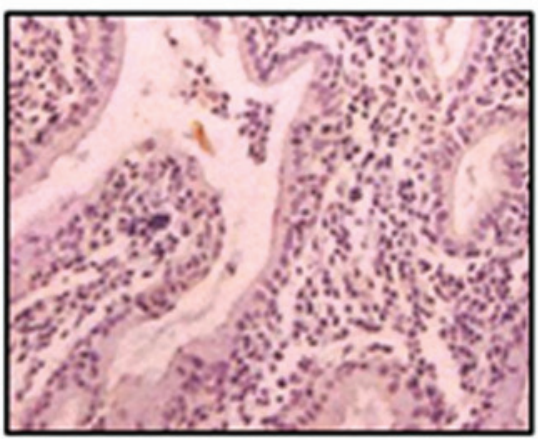

Adenocarcinoma tissue

B

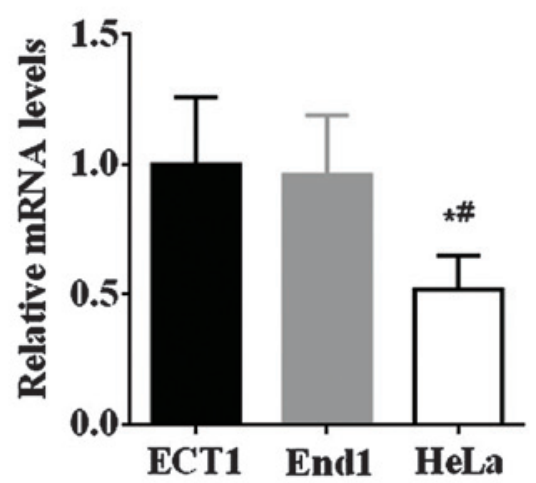

C

ECT1 End1 HeLa

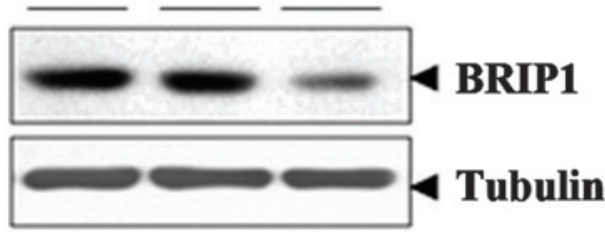

Figure 1. Expression of BRIP1 in cervical carcinoma tissues and cells. (A) BRIP1 expression (brown) was analyzed by immunohistochemistry (left panel, normal cervix tissue; middle panel, squamous cancer tissue; right panel, adenocarcinoma). Representative images are provided. Magnification, x200. (B) BRIP1 mRNA expression in normal cervix and HeLa cells was measured by reverse transcription-polymerase chain reaction. Data are expressed as the mean \pm standard deviation $(n=3)$. ${ }^{*} \mathrm{P}<0.05$ vs. the ECT1 cell group; ${ }^{\#} \mathrm{P}<0.05$ vs. the End1 cell group. (C) Western blot analysis of BRIP1 expression in normal cervix and HeLa cells. Tubulin was analyzed as the loading control. BRIP1, breast cancer 1, early onset-interacting protein 1; mRNA, messenger RNA.

the lower surface were fixed using cold methanol, stained with crystal violet (Sigma-Aldrich) and counted using light microscopy (Olympus BX53; Olympus Corporation, Tokyo, Japan).

Cell cycle assays. For the cell cycle assays, cells were seeded at a density of $1 \times 10^{5}$ cells into $6-\mathrm{cm}$ tissue culture dishes (Clontech Laboratories, Mountain View, CA, USA) and cells were synchronized at the G1 phase by serum starvation for $12 \mathrm{~h}$. Following $24 \mathrm{~h}$ of incubation, cells were washed using cold phosphate-buffered saline (PBS) and fixed with $70 \%$ cold alcohol overnight at $4^{\circ} \mathrm{C}$. The fixed cells were collected, washed with PBS and stained using propidium iodide (PI; Sigma-Aldrich) in the presence of RNase (Sigma-Aldrich). Flow cytometric (FCM; FACSCanto ${ }^{\mathrm{TM}}$; BD Biosciences) analysis was used to determine cell cycle distribution with the aid of ModFit LT software (Verity Software House, Topsham, ME, USA).

Apoptosis assays. Cell apoptosis was evaluated by FCM using an Annexin V-fluorescein isothiocyanate (FITC) apoptosis kit (Cell Signaling Technology) according to the manufacturer's protocol. Briefly, the cells were washed, resuspended with binding buffer, incubated with Annexin V-FITC and PI buffers for $15 \mathrm{~min}$ at $4^{\circ} \mathrm{C}$ in the dark and subsequently analyzed using FCM.

Western blot analysis. The cells were lysed on ice with RIPA buffer (Sigma-Aldrich). The protein concentration of the lysed cells was measured using the bicinchoninic acid protein assay reagent (Pierce Biotechnology, Inc., Rockford, IL, USA). Protein extracts $(50 \mu \mathrm{g})$ were separated using $10 \%$ sodium dodecyl sulfate-polyacrylamide gel electrophoresis at $100 \mathrm{~V}$, transferred onto polyvinylidene fluoride membranes (Invitrogen; Thermo Fisher Scientific) and analyzed by western blotting with monoclonal rabbit anti-human BRIP1 (cat. no. 4578; 1:1,000), cleaved caspase-3 (cat. no. 9661; 1:1,000), B-cell lymphoma 2 (cat. no. 2870; 1:1,000), tubulin (cat. no. 5335; 1:1,000), RhoA-GTP (cat. no. 2461; 1:1,000), RhoA (cat. no. 2117; 1:1,000), Ras-related C3 botulinum toxin substrate 1 (Rac1)-GTP (cat. no. 8815; 1:1,000) and monoclonal mouse anti-human Rac1 (cat. no. 4651; 1:1,000) antibodies (Cell Signaling Technology, Inc). Bands were detected with an enhanced chemiluminescence kit (GE Healthcare Life Sciences, Chalfont, UK) and visualized using the ChemiDoc ${ }^{\mathrm{TM}}$ XRS system (Bio-Rad Laboratories, Inc.).

Statistical analysis. The data obtained in the present study was analyzed using the statistical package SPSS version 17.0 (SPSS Inc., Chicago, IL, USA). Data are expressed as the mean \pm standard deviation from at least three independent experiments. For values that were normally distributed, a direct comparison between two groups was performed using an unpaired Student's t-test, and one-way analysis of variance with Dunnett's post-hoc test was utilized to compare the means of three or more groups. $\mathrm{P}<0.05$ was considered to indicate a statistically significant difference. 
A

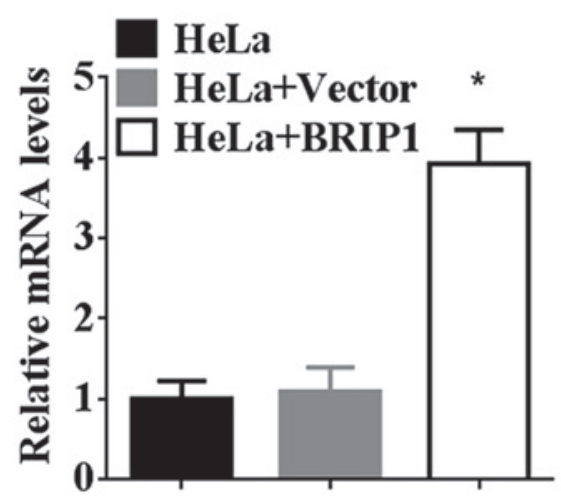

C

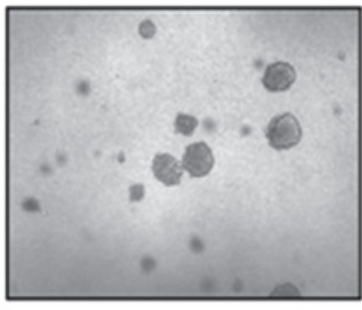

HeLa

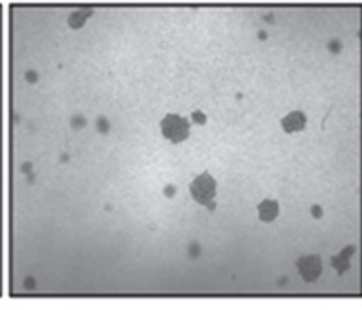

HeLa+Vector

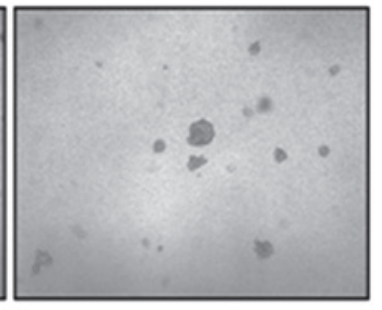

HeLa+BRIP1

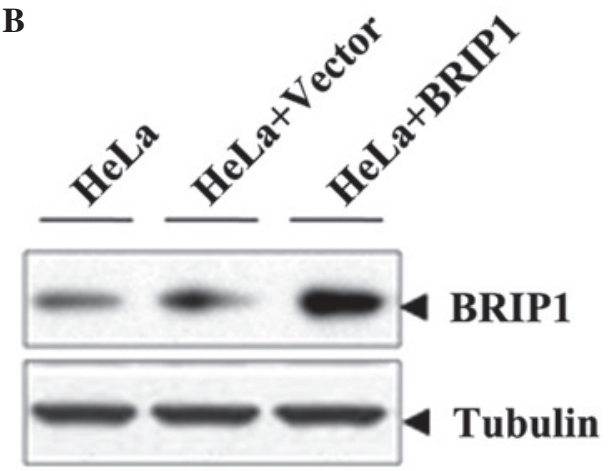

D

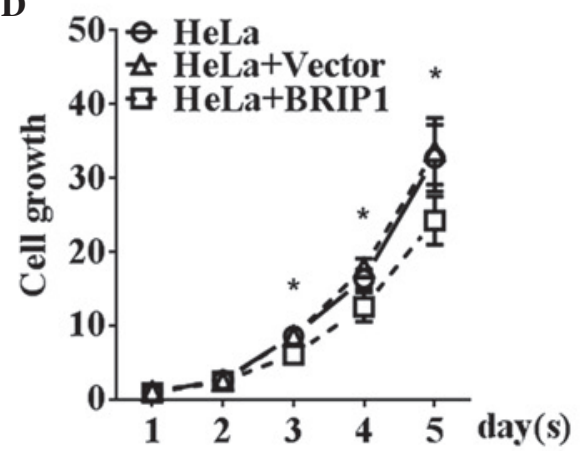

E

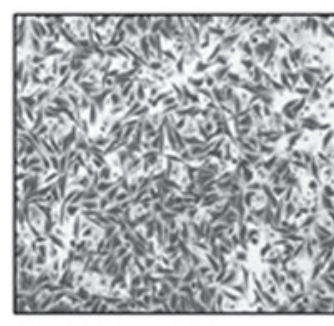

HeLa

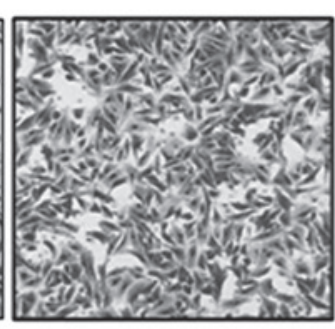

HeLa+Vector

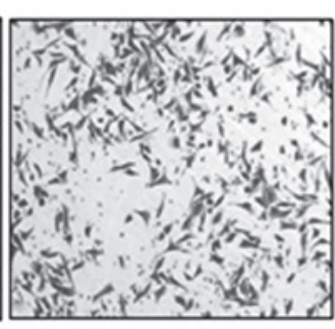

HeLa+BRIP1
F

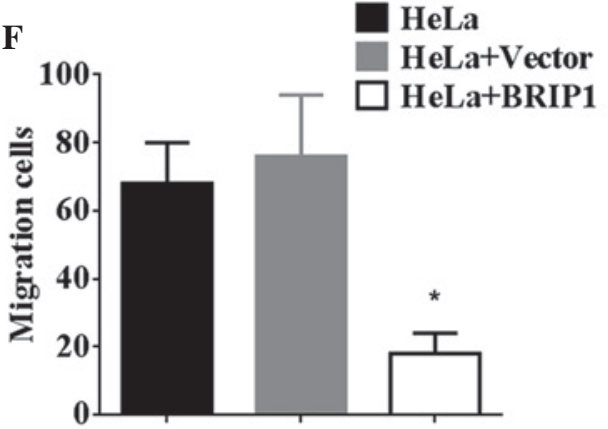

Figure 2. Expression of ectopic BRIP1 inhibited the tumorigenic properties of HeLa cells. HeLa cells were transfected with empty vector or BRIP1 recombinant plasmid for $48 \mathrm{~h}$. (A) Messenger RNA expression of BRIP1 in HeLa cells was measured by reverse transcription-quantitative polymerase chain reaction. Glyceraldehyde 3-phosphate dehydrogenase was used as an internal control. Data are expressed as the mean \pm standard deviation ( $\mathrm{n}=3$ ). ${ }^{*} \mathrm{P}<0.05$ vs. the HeLa+Vector group. (B) Protein expression of BRIP1 in HeLa cells was measured by western blot analysis. Tubulin was analyzed as a loading control. (C and D) Images (magnification, x200) and quantification of the growth of HeLa cells. Cell growth was monitored by 3-(4,5-dimethylthiazol-2-yl)-2,5-diphenyltetrazolium bromide. Absorbance at day 0 was assigned a value of 1 . Data are expressed as the mean \pm standard deviation ( $\mathrm{n}=3$ ). ${ }^{*} \mathrm{P}<0.05$ vs. the HeLa+Vector group. (E and F) Representative images and quantification of transmembrane HeLa cells. Number of transmembrane cells was quantified by counting 5 random high-power fields (magnification, $\mathrm{x} 40$ ) from each chamber. Data are expressed as the mean \pm standard deviation ( $\mathrm{n}=3$ ). ${ }^{*} \mathrm{P}<0.05 \mathrm{vs}$. the HeLa+Vector group. BRIP1, breast cancer 1, early onset-interacting protein 1.

\section{Results}

Expression of BRIP1 in human cervical cancer tissues. In order to investigate the characteristics of BRIP1 expression in normal cervix and cervical cancer tissues, 30 normal cervix tissue samples and 225 cervical cancer samples were analyzed using RT-qPCR. The clinicopathological data from the 255 cervical cancer samples is summarized in Table I. Decreased BRIP1 mRNA expression was observed in the cervical cancer patient group. Furthermore, the reduction in BRIP1 expression correlated significantly with unfavorable variables, including the International Federation of Gynecologists and Obstetricians (FIGO) stage and the presence of lymph node metastases. However, no significant differences were observed between the groups when compared according to any other clinicopathological feature, including age, histological type and level of differentiation.
In addition, immunostaining data revealed that the expression of BRIP1 protein was markedly decreased in the cervical cancer samples (squamous cancer and adenocarcinoma) compared with the normal cervix tissue samples (Fig. 1A). Furthermore, the expression of BRIP1 was detected in normal cervical cell lines (End1 and Ect1) and a cervical cancer cell line (HeLa). In line with these results, HeLa cells exhibited lower BRIP1 mRNA and protein levels compared with End1 and Ect1 cells ( $\mathrm{P}<0.05$; Fig. $1 \mathrm{~B}$ and $\mathrm{C})$.

Overexpression of BRIP1 inhibits the tumorigenic properties of HeLa cells. In order to elucidate the role of BRIP1 in cervical cancer, BRIP1 was overexpressed in HeLa cells via transfection with the BRIP1 recombinant plasmid. RT-qPCR and western blot analyses revealed that BRIP1 mRNA and protein levels were markedly elevated following BRIP1 recombinant plasmid 
Table I. Correlation of BRIP1 expression with clinicopathological features in cervical cancer.

Clinicopathological feature

Tissue type

Normal cervix

Carcinoma

Age, years

$>40$

$\leq 40$

21

Other

Degree of differentiation

Well 35

Moderate 108

Poor $\quad 82$

FIGO stage

I 141

II $\quad 72$

III-IV 12

Lymph node metastasis

Negative

132

Positive
$1.215 \pm 0.249$
$0.587 \pm 0.176$

$0.647 \pm 0.134$

$0.556 \pm 0.146$

$0.595 \pm 0.204$

$0.573 \pm 0.108$

0.418

$0.571 \pm 0.127$

0.580

$0.615 \pm 0.122$

$0.633 \pm 0.143$

0.539

$0.645 \pm 0.173$

0.783

$0.778 \pm 0.103$

$0.623 \pm 0.098$

0.022

$0.402 \pm 0.189$

0.009

$0.678 \pm 0.132$

$0.439 \pm 0.139$

BRIP1, breast cancer 1, early onset-interacting protein 1; FIGO, International Federation of Gynecology and Obstetrics Cancer.

A

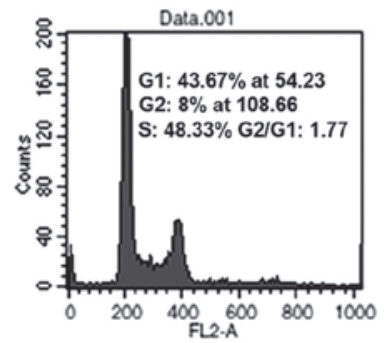

HeLa

C

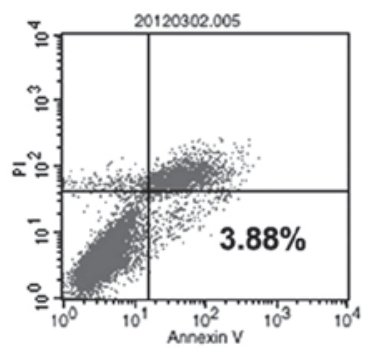

HeLa

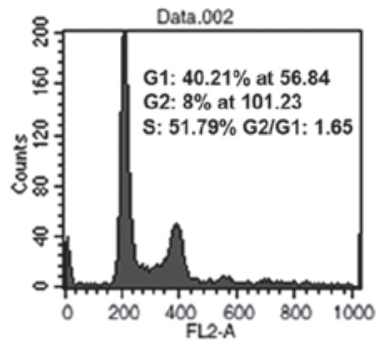

HeLa+Vector

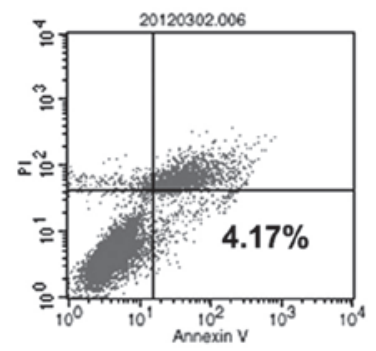

HeLa+Vector

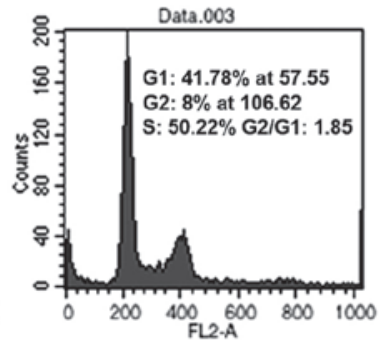

HeLa+BRIP1

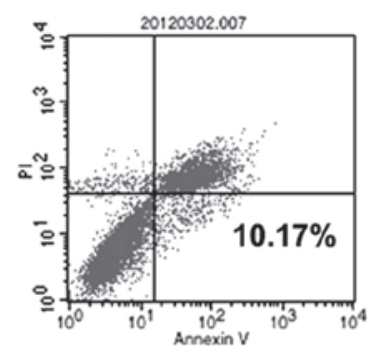

HeLa+BRIP1

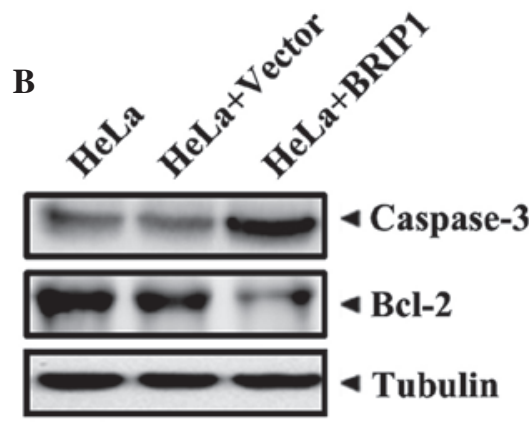

D

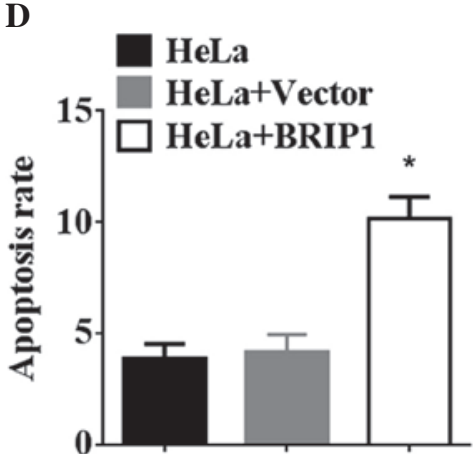

Figure 3. Overexpression of BRIP1 induces HeLa cell apoptosis. HeLa cells were transfected with empty vector or BRIP1 recombinant plasmid for $48 \mathrm{~h}$. (A) Cell cycle of the control and BRIP1-overexpressing HeLa cells was analyzed by FCM. Data presented are representative of three independent experiments. (B) Western blot analysis of cleaved caspase-3 and Bcl-2 expression. Tubulin was analyzed as the loading control. (C) Apoptosis of the control and BRIP1-overexpressing HeLa cells was analyzed by FCM. Data presented are representative of three independent experiments. (D) Statistical analysis of the apoptosis rate. Data are expressed as the mean \pm standard deviation $(n=3)$. ${ }^{*} \mathrm{P}<0.05$ vs. the HeLa+Vector group. BRIP1, breast cancer 1, early onset-interacting protein 1; FCM, flow cytometry; Bcl-2, B-cell lymphoma. 
Table II. Impact of BRIP1 expression on cell adhesion, $\mathrm{n}=5$.

Cell adhesion rate, $\%$

\begin{tabular}{lccc}
\cline { 2 - 4 } Group & $20 \mathrm{~min}$ & $40 \mathrm{~min}$ & $60 \mathrm{~min}$ \\
\hline HeLa & $11.5 \pm 0.12$ & $35.7 \pm 2.33$ & $53.8 \pm 2.13$ \\
HeLa+Vector & $10.3 \pm 0.98$ & $38.6 \pm 3.18$ & $51.5 \pm 1.48$ \\
HeLa+BRIP1 & $8.6 \pm 1.24^{\mathrm{a}}$ & $21.7 \pm 2.41^{\mathrm{a}}$ & $38.6 \pm 2.37^{\mathrm{a}}$ \\
P-value & 0.003 & 0.001 & 0.001
\end{tabular}

Data are expressed as the mean \pm standard deviation. ${ }^{a} \mathrm{P}<0.05$ vs. the HeLa+Vector group. BRIP1, breast cancer 1 , early onset-interacting protein 1 .

A

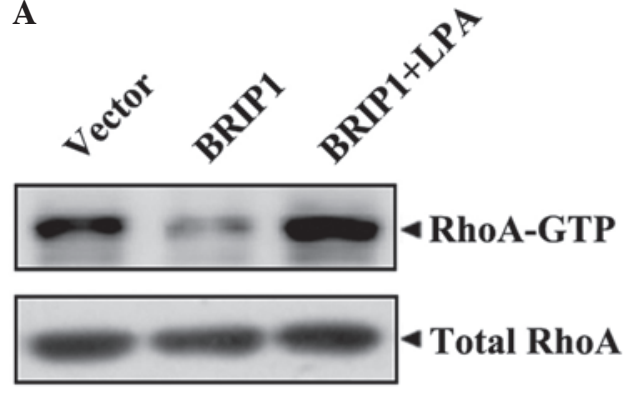

D

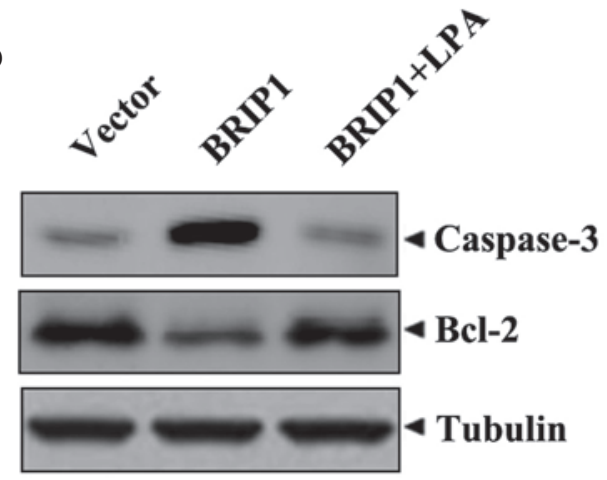

B

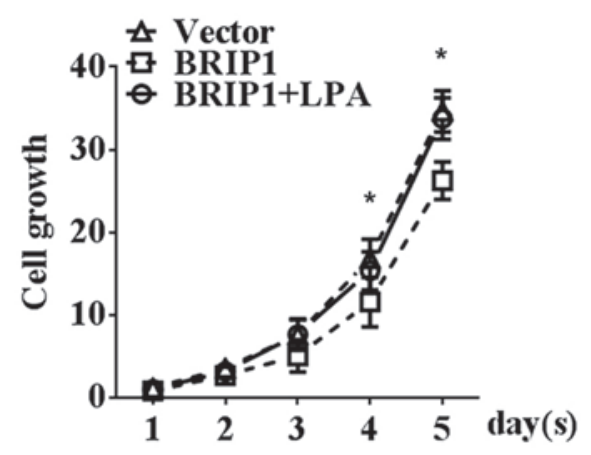

$\mathbf{E}$

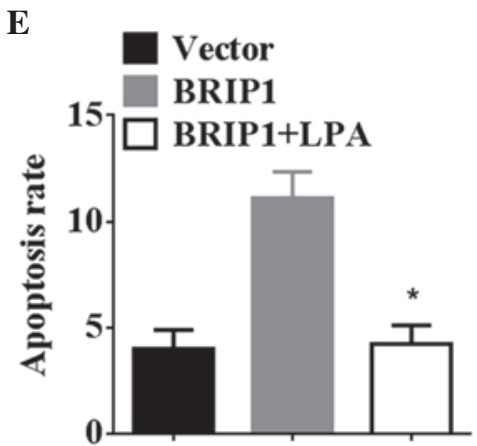

C

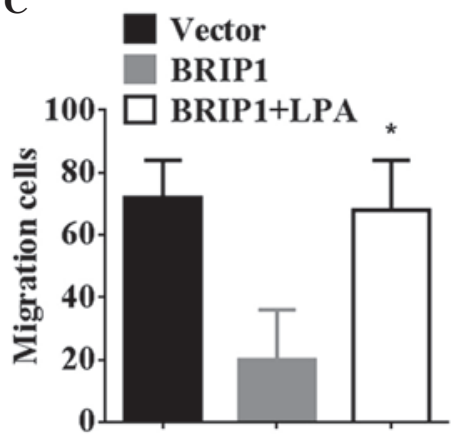

Figure 4. Attenuation in tumorigenic properties obtained by BRIP1 overexpression is reversed by LPA, an agonist of RhoA GTPase. Forty-eight hours subsequent to the transfection of HeLa cells with BRIP1, the cells were pretreated with saline or LPA (5 $\mu \mathrm{M}$ ) for 24 h. (A) Expression of RhoA-GTP and total RhoA was analyzed by western blotting. (B) Cell growth was monitored by 3-(4,5-dimethylthiazol-2-yl)-2,5-diphenyltetrazolium bromide. Absorbance at day 0 was assigned a value of 1 . Data are expressed as the mean \pm standard deviation ( $=3$ ). * $<<0.05$ vs. the BRIP1+saline group. (C) Quantification of transmembrane HeLa cells. Data are expressed as the mean \pm standard deviation $(n=3)$. $P<0.05$ vs. the BRIP1+saline group. (D) Western blot analysis of cleaved caspase-3 and Bcl-2 expression. Tubulin was analyzed as the loading control. (E) Quantification of the rate of apoptosis of HeLa cells. Data are expressed as the mean \pm standard deviation $(n=3)$. $P<0.05$ vs. the BRIP1+saline group. BRIP1, breast cancer 1, early onset-interacting protein 1 ; LPA, Lysophosphatidic acid; Bcl-2, B-cell lymphoma 2; RhoA GTP, Ras homolog gene family, member A guanosine-5'-triphosphatease.

transfection, compared with the control groups $(\mathrm{P}<0.05$; Fig. 2A and B). The MTT proliferation assay results revealed that BRIP1 overexpression significantly suppressed the growth of HeLa cells in a time-dependent manner $(\mathrm{P}<0.05$; Fig. $2 \mathrm{C}$ and D). Similarly, ectopic expression of BRIP1 attenuated the invasive ability of HeLa cells, led to a reduction in the number of invasive cells ( $\mathrm{P}<0.05$; Fig. $2 \mathrm{E}$ and $\mathrm{F}$ ). Additionally, BRIP1 overexpression in HeLa cells decreased the cell adhesion rate at the indicated time points $(20,40$ and $60 \mathrm{~min}$; Table II). Collectively, the results of the present study confirmed that BRIP1 overexpression significantly inhibited the tumorigenic properties of HeLa cells in vitro.
BRIPl induces apoptosis in HeLa cells. In order to identify the antitumorigenic mechanism of BRIP1 in cervical cancer, the cell cycle and cell apoptosis were analyzed in HeLa cells following transfection with BRIP1 and control vectors. The results demonstrate that ectopic expression of BRIP1 in HeLa cells did not affect the cell cycle distribution (Fig. 3A). In addition, the levels of pro-apoptotic proteins (caspase-3 and Bcl-2) were detected in BRIP1-overexpressing HeLa cells. Western blot analysis demonstrated that BRIP1 overexpression upregulated cleaved caspase-3 and downregulated Bcl-2 protein in HeLa cells (Fig. 3B). Moreover, BRIP1 overexpression in HeLa cells significantly increased the percentage of apoptotic cells 
( $\mathrm{P}<0.05$; Fig. 3C and D). Thus, BRIP1 overexpression-induced cell apoptosis may suppress the growth of HeLa cells.

RhoA GTPases are critical for the antitumor effects of BRIPl in HeLa cells. The alteration of Rho GTPase activity in BRIP1-overexpressing HeLa cells was assessed. The western blotting results demonstrated that BRIP1 overexpression was able to significantly reduce the levels of RhoA-GTP in HeLa cells (Fig. 4A). In order to determine whether the inhibitory tumorigenic properties obtained by BRIP1 overexpression were associated with the activity of RhoA GTPase, BRIP1-overexpressing HeLa cells were treated with the RhoA GTPase agonist LPA, and their tumorigenic properties were then evaluated. As demonstrated in Fig. 4B, the growth of the BRIP1-overexpressing HeLa cells was markedly elevated following LPA treatment $(\mathrm{P}<0.05)$. Similar results were observed in the Transwell migration assay $(\mathrm{P}<0.05$; Fig. 4C). The apoptosis assay revealed that LPA treatment decreased the levels of cleaved caspase-3, increased Bcl-2 protein levels (Fig. 4D) and reversed the apoptotic inhibitory effect of BRIP1 overexpression $(\mathrm{P}<0.05$; Fig. 4E).

\section{Discussion}

Cervical cancer remains a significant health problem for women in developing countries (20). Although there have been significant advances in the diagnosis of cervical cancer over the last decade, cervical cancer has a high mortality rate, as the majority of patients are initially diagnosed in the advanced stages of the disease $(4,21)$. The treatment for pre-invasive lesions is typically based on surgery, and for invasive cervical cancers, the treatment consists of surgery and/or radiation and cisplatin-based chemotherapy $(22,23)$. However, a large proportion of patients will go on to develop drug resistance during treatment (24). In-depth investigations concerning the molecular mechanisms of cervical cancer are required to promote the development of novel effective molecular targeted drugs.

The BRIP1 gene encodes a helicase that interacts with BRCA1, which is crucial for DNA repair and genomic stability (14). Studies have suggested that BRIP1 possesses an anti-oncogenic role, and that frequently observed single nucleotide polymorphisms (SNPs) in the BRIP1 gene may be associated with susceptibility to breast, prostate and ovarian cancer $(18,25,26)$. Current evidence has revealed that SNPs in the BRIP1 gene may be capable of influencing cervical cancer susceptibility and that BRIP1 gene variations are potentially implicated in the development and progression of cervical cancer $(14,15)$. The results of the present study support the observations made in previous studies, and furthermore, have identified that BRIP1 is downregulated in cervical carcinoma tissue. In addition, significant correlations were observed between the reduction in BRIP1 expression and unfavorable variables, including FIGO stage and presence of lymph node metastases. Functionally, the plasmid-mediated overexpression of BRIP1 inhibited the carcinogenesis of cervical cancer, which suggested that the BRIP1 gene may possess the role of a tumor suppressor in cervical cancer development.

The present study additionally identified that BRIP1 overexpression suppressed RhoA GTPase activity in cervical cancer cells, and that the inhibitory tumorigenic properties obtained as a result of BRIP1 overexpression were significantly reversed by the activation of RhoA GTPase. RhoA GTPase is part of the Ras superfamily of small GTPases, and its activation can induce the assembly of basal stress fibers and cytoskeleton-mediated changes in cell motility (27). A number of previous studies have supported the role of RhoA GTPase in cell proliferation, adhesion, apoptosis, cell polarity, invasion and metastasis (28-30). A previous study provided evidence that RhoA GTPase may be associated with metastasis of cervical cancer and that its functioning is mediated by a mitogen-activated protein kinase/extracellular signal-regulated kinase-dependent mechanism $(31,32)$, implying that the involvement of alterations in the activation of RhoA GTPase in events may have a role in cervical cancer carcinogenesis. Overall, BRIP1 suppressed the tumorigenic properties of cervical cancer via the downregulation of RhoA GTPase activity.

In conclusion, the results of the present study may provide some insight into the functioning of BRIP1 in cervical cancer. BRIP1 may act as an essential DEAH helicase that is capable of regulating the tumorigenic properties of cervical cancer by controlling RhoA GTPase. BRIP1 may prove to be a potential tumor suppressor gene in cervical cancer and may assist with uncovering further associations between RhoA GTPase and cervical cancer. BRIP1 may constitute a promising candidate for cervical cancer therapy.

\section{Acknowledgements}

The present study was supported by the National Natural Science Foundation of China (grant nos. 81101959 and 81101958).

\section{References}

1. Arbyn M, Castellsagué X, de Sanjosé S, Bruni L, Saraiya M, Bray F and Ferlay J: Worldwide burden of cervical cancer in 2008. Ann Oncol 22: 2675-2686, 2011.

2. Jemal A, Bray F, Center MM, Ferlay J, Ward E and Forman D: Global cancer statistics. CA Cancer J Clin 61: 69-90, 2011.

3. Jemal A, Siegel R, Ward E, Hao Y, Xu J and Thun MJ: Cancer statistics, 2009. CA Cancer J Clin 59: 225-249, 2009.

4. Balacescu O, Balacescu L, Tudoran O, Todor N, Rus M, Buiga R, Susman S, Fetica B, Pop L, Maja L, et al: Gene expression profiling reveals activation of the FA/BRCA pathway in advanced squamous cervical cancer with intrinsic resistance and therapy failure. BMC Cancer 14: 246, 2014.

5. Lippert TH, Ruoff HJ and Volm M: Intrinsic and acquired drug resistance in malignant tumors. The main reason for therapeutic failure. Arzneimittelforschung 58: 261-264, 2008.

6. Benjamin I, Saigo P, Finstad C, Takahashi H, Federici M, Rubin SC and Boyd J: Expression and mutational analysis of P53 in stage IB and IIA cervical cancers. Am J Obstet Gynecol 175: 1266-1271, 1996 .

7. Kim JW, Roh JW, Park NH, Song YS, Kang SB and Lee HP: Polymorphism of TP53 codon 72 and the risk of cervical cancer among Korean women. Am J Obstet Gynecol 184: 55-58, 2001.

8. Singh H, Sachan R, Devi S, Pandey SN and Mittal B: Association of GSTM1, GSTT1, and GSTM3 gene polymorphisms and susceptibility to cervical cancer in a North Indian population. Am J Obstet Gynecol 198: 303.e1-6, 2008.

9. Cantor SB, Bell DW, Ganesan S, Kass EM, Drapkin R, Grossman S, Wahrer DC, Sgroi DC, Lane WS, Haber DA and Livingston DM: BACH1, a novel helicase-like protein, interacts directly with BRCA1 and contributes to its DNA repair function. Cell 105: 149-160, 2001.

10. Yu X, Chini CC, He M, Mer G and Chen J: The BRCT domain is a phospho-protein binding domain. Science 302: 639-642, 2003.

11. Cantor S, Drapkin R, Zhang F, Lin Y, Han J, Pamidi S and Livingston DM: The BRCA1-associated protein BACH1 is a DNA helicase targeted by clinically relevant inactivating mutations. Proc Natl Acad Sci USA 101: 2357-2362, 2004. 
12. Peng M,Litman R, Jin Z, Fong $\mathrm{G}$ and Cantor SB: BACH1 is a DNA repair protein supporting BRCA1 damage response. Oncogene 25: 2245-2253, 2006.

13. Tu Z, Aird KM, Bitler BG, Nicodemus JP, Beeharry N, Xia B, Yen TJ and Zhang R: Oncogenic RAS regulates BRIP1 expression to induce dissociation of BRCA1 from chromatin, inhibit DNA repair, and promote senescence. Dev Cell 21: 1077-1091, 2011.

14. Ma XD, Cai GQ, Zou W, Huang YH, Zhang JR, Wang DT and Chen BL: First evidence for the contribution of the genetic variations of BRCA1-interacting protein 1 (BRIP1) to the genetic susceptibility of cervical cancer. Gene 524: 208-213, 2013.

15. Ma XD, Cai GQ,Zou W, Huang YH,Zhang JR, Wang DT and Chen BL: BRIP1 variations analysis reveals their relative importance as genetic susceptibility factor for cervical cancer. Biochem Biophys Res Commun 433: 232-236, 2013.

16. Narayan G, Arias-Pulido H, Nandula SV, Basso K, Sugirtharaj DD, Vargas H, Mansukhani M, Villella J, Meyer L, Schneider A, et al: Promoter hypermethylation of FANCF: Disruption of Fanconi Anemia-BRCA pathway in cervical cancer. Cancer Res 64: 2994-2997, 2004.

17. Levitus M, Waisfisz Q, Godthelp BC, de Vries Y, Hussain S, Wiegant WW, Elghalbzouri-Maghrani E, Steltenpool J, Rooimans MA, Pals G, et al: The DNA helicase BRIP1 is defective in Fanconi anemia complementation group J. Nat Genet 37: 934-935, 2005

18. Song H, Ramus SJ, Kjaer SK, Hogdall E, Dicioccio RA, Whittemore AS, McGuire V, Hogdall C, Jacobs IJ, Easton DF, et al: Tagging single nucleotide polymorphisms in the BRIP1 gene and susceptibility to breast and ovarian cancer. PLoS One 2: e268, 2007.

19. Rafnar T, Gudbjartsson DF, Sulem P, Jonasdottir A, Sigurdsson A, Jonasdottir A, Besenbacher S, Lundin P, Stacey SN Gudmundsson J, et al: Mutations in BRIP1 confer high risk of ovarian cancer. Nat Genet 43: 1104-1107, 2011.

20. Comparetto $C$ and Borruto F: Cervical cancer screening: A neverending developing program. World J Clin Cases 3: 614-624, 2015.

21. Schiffman M, Wentzensen N, Wacholder S, Kinney W, Gage JC and Castle PE: Human papillomavirus testing in the prevention of cervical cancer. J Natl Cancer Inst 103: 368-383, 2011.

22. Salicrú SR, de la Torre JF and Gil-Moreno A: The surgical management of early-stage cervical cancer. Curr Opin Obstet Gynecol 25: 312-319, 2013.
23. Movva S, Rodriguez L, Arias-Pulido $\mathrm{H}$ and Verschraegen $\mathrm{C}$ : Novel chemotherapy approaches for cervical cancer. Cancer 115: 3166-3180, 2009.

24. Casagrande N, De Paoli M, Celegato M, Borghese C, Mongiat M, Colombatti A and Aldinucci D: Preclinical evaluation of a new liposomal formulation of cisplatin, lipoplatin, to treat cisplatin-resistant cervical cancer. Gynecol Oncol 131: 744-752, 2013.

25. Kote-Jarai Z, Jugurnauth S, Mulholland S, Leongamornlert DA, Guy M, Edwards S, Tymrakiewitcz M, O'Brien L, Hall A, Wilkinson R, et al; UKGPCS Collaborators; British Association of Urological Surgeons' Section of Oncology: A recurrent truncating germline mutation in the BRIP1/FANCJ gene and susceptibility to prostate cancer. Br J Cancer 100: 426-430, 2009

26. Wong MW, Nordfors C, Mossman D, Pecenpetelovska G, Avery-Kiejda KA, Talseth-Palmer B, Bowden NA and Scott RJ: BRIP1, PALB2, and RAD51C mutation analysis reveals their relative importance as genetic susceptibility factors for breast cancer. Breast Cancer Res Treat 127: 853-859, 2011

27. Leve F and Morgado-Díaz JA: Rho GTPase signaling in the development of colorectal cancer. J Cell Biochem 113: 2549-2559, 2012.

28. Tas PW, Gambaryan S and Roewer N: Volatile anesthetics affect the morphology of rat glioma C6 cells via RhoA, ERK, and Akt activation. J Cell Biochem 102: 368-376, 2007.

29. Struckhoff AP, Rana MK and Worthylake RA: RhoA can lead the way in tumor cell invasion and metastasis. Front Biosci (Landmark Ed) 16: 1915-1926, 2011

30. Liu M, Lang N, Chen X, Tang Q, Liu S, Huang J, Zheng Y and Bi F: miR-185 targets RhoA and Cdc42 expression and inhibits the proliferation potential of human colorectal cells. Cancer Lett 301: 151-160, 2011.

31. Hamadmad SN and Hohl RJ: Erythropoietin stimulates cancer cell migration and activates RhoA protein through a mitogen-activated protein kinase/extracellular signal-regulated kinase-dependent mechanism. J Pharmacol Exp Ther 324: 1227-1233, 2008.

32. He M, Cheng Y, Li W, Liu Q, Liu J, Huang J and Fu X: Vascular endothelial growth factor $\mathrm{C}$ promotes cervical cancer metastasis via up-regulation and activation of RhoA/ROCK-2/moesin cascade. BMC Cancer 10: 170, 2010. 